\title{
Efek Variasi Suhu Pack Carburizing Baja St 41 terhadap Kekerasan dan Kekuatan Impak
}

\author{
Ramlan* dan Amin Bahma \\ Jurusan Fisika FMIPA Universitas Sriwijaya, Palembang, Sumatera Selatan \\ E-mail: *ramlan@unsri.ac.id \\ Direvisi : 7 Maret 2020 \\ Disetujui : 20 Maret 2020
}

Masuk :11 Februari 2020

\begin{abstract}
Abstrak: Proses pack carburizing adalah proses pengerasan permukaan baja, pada penelitian ini dilakukan proses pack carubirizing baja ST 41 untuk mengetahui perubahan nilai kekerasan dan kekuatan impaknya. Baja ST 41 tergolong baja karbon rendah, melalui proses tersebut bertujuan untuk mengeraskan permukaan baja ST 41 dan didalam baja masih lunak agar keuletan baja ST 41 masih bisa dipertahankan. Proses pack carburizing dilakukan dengan menimbun baja ST 41 dengan serbuk karbon dari arang kayu, kemudian di panaskan dengan variasi suhu yaitu 700,750 dan $800^{\circ} \mathrm{C}$ dengan waktu penahanan untuk masing -masing suhu selama 30 menit. Setelah dilakukan pemanasan selanjutnya di quenching kedalam media air. Sampel yang telah mengalami pack carburizing selanjutnya di ukur kekerasan nya menggunakan Rockwell dan dilakukan uji impak Charpy untuk melihat tingkat kegetasan baja. Dari hasil pengukuran kekerasan diperoleh nilai kekerasan tertinggi pada sampel dengan suhu pemanasan $800^{\circ} \mathrm{C}$ yaitu sebesar $32 \mathrm{HRC}$ dan memiliki nilai kuat impak sebesar 1,993 joule $/ \mathrm{mm}^{2}$. Bila dibandingkan dengan sampel sebelum proses pack carburizing, terjadi peningkatan kekerasan hampir dua kali lipat sedangkan nilai kuat impaknya juga terjadi peningkatan sebesar $10 \%$
\end{abstract}

Kata kunci: ST41, pack carburizing, quenching, kekerasan rock well, impak charpy

Abstract: The pack carburizing process is a process of hardening the surface of the steel. In this study, a pack carubirizing process of ST 41 steel was carried out to determine changes in the value of its hardness and impact strength. ST 41 steel is classified as low carbon steel, through this process it aims to harden the surface of ST 41 steel and the inside of the steel is still soft so that the ductility of ST 41 steel can still be maintained. The pack carburizing process is carried out by stockpiling ST 41 steel with carbon powder from wood charcoal, then heating it with temperature variations, namely 700,750 and $800 \circ \mathrm{C}$ with holding times for each temperature for 30 minutes. After heating, it is quenched into the water medium. Samples that have undergone pack carburizing are then measured for their hardness using Rockwell and a Charpy impact test is carried out to see the degree of brittleness of the steel. From the hardness measurement results, the highest hardness value was obtained in the sample with a heating temperature of $800 \mathrm{oC}$, which was $32 \mathrm{HRC}$ and had an impact strength value of 1.993 joules / mm2. When compared with the sample before the pack carburizing process, the hardness almost doubled while the impact strength value also increased by $10 \%$.

Keywords: ST41, pack carburizing, quenching, rock well hardness, charpy impact

\section{PENDAHULUAN}

Perkembangan ilmu pengetahuan dan teknologi berperan penting dalam perkembangan teknologi dan industri salah satunya dibidang otomotif dan industri-industri komponen atau peralatanpertanian. Khususnya untuk merekayasa material logam agar menjadi material yang keras dan tingkat keuletan baja masih bisa dipertahankan. Proses pengerasan baja secara umum dapat dilakukan salah satunya melalui proses hardenning yaitu dipanaskan sampai suhu austenit kemudian didinginkan secara cepat [1]. Melalui proses ini logam baja akan mengalami peningkatan kekerasan tetapi akan cenderung menjadi getas [1,2]. Beberapa material untuk 
komponen permesinan atau peralatan pertanian memerlukan material yang keras sebatas dipermukaan dan tetap lunak di bagian dalam, agar baja tersebut masih tetap ulet. Untuk memperoleh material dengan sifat seperti tersebut perlu dilakukan proses surface hardenning yaitu melalui proses pack carburizing [3]. Mekanisme proses pack carburizing adalah dengan jalan mendifusikan unsur $\mathrm{C}$ (karbon) ke permukaan logam pada suhu tinggi sehingga terjadi pembentukan austenit atau martensit di permukaan baja, sehingga menyebabkan material baja menjadi keras dis ebatas permukaan [3,4]. Kesempurnaan proses difusi karbon pada permukaan baja sangat dipengaruhui beberapa faktor antara lain : tingginya suhu pemanasan, dan tingkat kehalusan bahan karbon[4]. Beberapa penulis melaporkan bahwa laju difusi karbon juga tergantung pada jenis karbon, karbon berasal dari carbon black memberikan laju difusi paling besar dibandingkan dengan karbon dari bio mass [5]. Proses pack carburizing umumnya dipergunakan untuk pengerasan baja dengan kadar karbon rendah, sedangkan baja karbon rendah tidak dapat diperkeras melalui proses hardenning. Baja ST 41 tergolong jenis baja karbon rendah yaitu dengan kadar C sekitar 0.01-0.04 \% [6]. Pada penelitian ini dilakukan proses penegerasan baja ST 41 menggunakan metoda pack carburizing dengan memakai unsur $\mathrm{C}$ dari serbuk arang kayu. Tujuan dari penelitian ini adalah untuk mengetahui pengaruh variasi suhu pack carburizing terhadap kekerasan dan kekuatan impaknya.

\section{METODOLOGI}

Untuk penelitian ini digunakan logam baja ST 41, bahan karbon dari arang kayu yang telah dihaluskan dan lolos ayakan 100 mesh. Baja ST41 ditempatkan di dalam cawan keramik kemudian di pendam dengan menggunakan serbuk arang kayu sampai seluruh permukaan baja tertutup oleh serbuk karbon. Selanjutnya sampel tersebut di panaskan menggunakan tungku listrik denga suhu divariasikan yaitu : 700,750 dan $800^{\circ} \mathrm{C}$ dan ditahah selama 30 menit untuk masing-masing suhu tersebut. Selanjutnya setelah di tahan selama 30 menit kemudian di keluarkan daru tungku dan dicelupkan kedalam air.

Sampel-sampel setelah dilakukan proses pack karburizing selanjutnya di ukur kekerasan permukaan nya menggunakan kekerasan Rockwell denag beban $400 \mathrm{~g}$ serta menggunakan idenstor diomond kerucut. Selain itu dilakukan pengujian impak charpy, ukuran sampel yang digunakan 55x 10 x $10 \mathrm{~mm}$. Nilai kuat impak dihitung berdasarkan persamaan sebagai berikut :

$$
\text { Kuat impak }=\text { m.g.h }(\operatorname{Cos} \alpha-\operatorname{Cos} \beta)
$$

dimana :

$$
\begin{aligned}
& \mathrm{m}=\text { massa bandul, } \mathrm{kg} \\
& \mathrm{g}=\text { gravitasi } \\
& \mathrm{h}=\text { panjang lengan bandul, } \mathrm{m} \\
& \mathrm{A}=\text { luasan dibawah takikan, } \mathrm{mm}^{2} \\
& \alpha=\text { sudut ayun awal } \\
& \beta=\text { audut ayun setelah benturan }
\end{aligned}
$$

\section{HASIL DAN PEMBAHASAN}

\section{Hasil pengujian kekerasan}

Uji kekerasan dilakukan sebanyak 5 kali uji dalam setiap sampel kemudian dihitung nilai rata-ratanya. Pada Gambar 1 diperlihatkan hasil nilai kekerasan sebagai fungsi suhu pemanasan. 


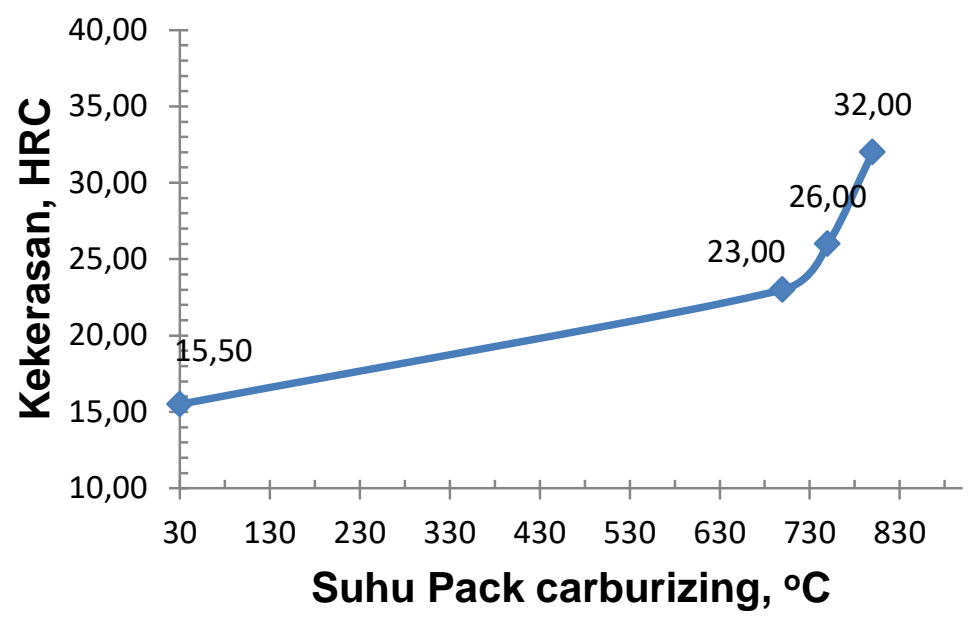

Gambar 1. Kurva hubungan kekerasan dengan suhu pack carburing.

Dari Gambar 1 diperlihatkan bahwa semakin tinggi suhu pack carburizing maka nilai kekerasan cenderung meningkat. Hal ini nmenunjukkan tingkat laju diffusi unsur karbon selama proses pack carburizing cenderung meningkat, karena terjadi peningkatan kekerasan. Nilai tertinggi diperoleh keketrasan sebesar 31 HRC pada sampel dengan suhu pemanasan $800^{\circ} \mathrm{C}$.

\section{Hasil pengujian kuat impak}

Hasil uji kuat impak diperlihatkan pada Gambar 2 sebagai berikut. Berdasarkan hasil yang diperlihatkan pada Gambar 2 menujukkan bahwa nilai kuat impak cenderung meningkat dan nilaiimpaktertinggi dicapai sebesar 32 joule $/ \mathrm{mm}^{2}$. Umumnya baja semakin keras cenderung menjadi getas yang ditandai dengan menurunnya nilai kuat impak, tetapi pada penelitian ini nilai kuat impak nya meningkat, bearti baja yang elah mengalami proses pack carburizing masih bersifat ulet.

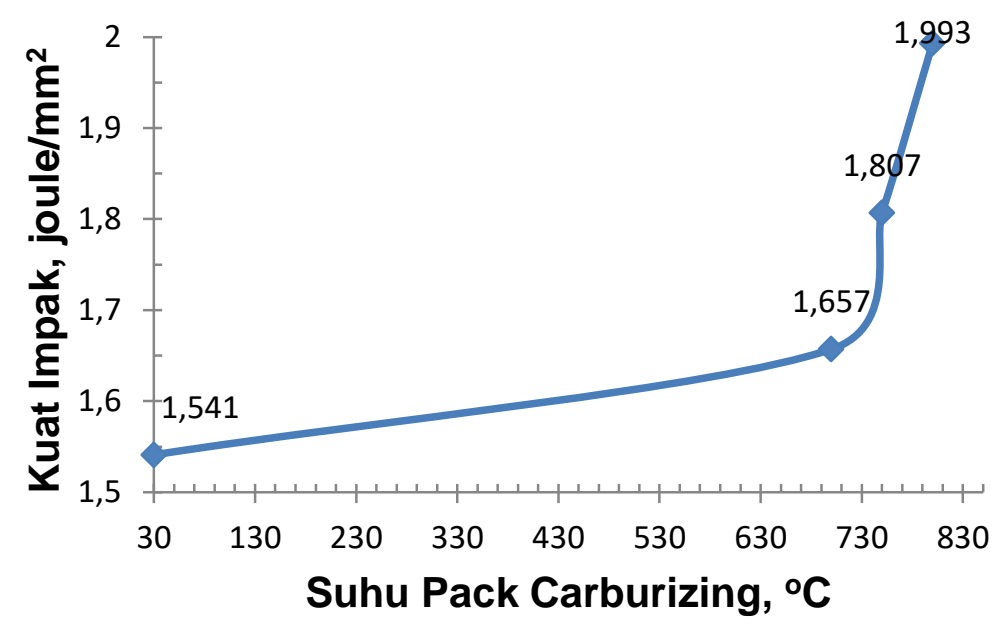

Gambar 2. Kurva hubungan kuat impak terhadap suhu pack carburizing.

\section{KESIMPULAN}

Suhu proses pack carburizing memberikan pengaruh yang signifikan terhadap peningkatan kekerasan maupun kuat impaknya, nilai tertinggi untuk kekerasan adalah 32 HRC dan kuat impaknya adalah 1,993 joule $/ \mathrm{mm}^{2}$. Dari hasil yang diperoleh bahwa baja ST 41 setelah proses pack carburizing akan menjadi keras di permukaan dan baja tersebut tepat menujukkan keuletannya. 


\section{DAFTAR PUSTAKA}

[1] Avala Lava Kumar, LECTURE NOTES ON MM-15-015 : HEAT TREATMENT, Department of Metallurgical \& Materials Engineering (MME), 2015

[2] Dr. Vivek Roy, Unit 5: Heat Treatment Processes, Engineering Materials, Cabin 15, R: 55 - 302, 2008.

[3] Dewa Ngakan Ketut Putra Negara, I Dewa Made Kirshna Muku, Pack Carburizing Baja Karbon Rendah, Jurnal Energi dan Manufaktur Vol.7, No.1, April 2015: 111-230.

[4] Bambang Kuswanto, Perlakuan pack carburizing pada baja karbon rendah sebagai material altrenatif untuk pisau potong pada penerapan teknologi tepat guna, Prosiding Seminar Nasional Sains dan Teknologi 2010 Fakultas Teknik Universitas Wahid Hasyim Semarang

[5] Mirantie Dwiharsanti, Winda Sri Jaman dan Shinta Virdhian, Design of experiment of low carbon steel resulted from pack carburizing process by factorial experiment method, Jurnal Riset Industri Vol. 10 No. 2, Agustus 2016, Hal. 92-97 .

[6] Media Nofri, Acang Taryana, Analisis sifat mekanik baja skd 61 dengan baja st 41 dilakukan hardening dengan variasi temperatur, BINA TEKNIKA, Volume 13 Nomor 2, Edisi Desember 2017, $189-199$ 